\title{
CORTA, PERO NO MALA: NOTAS SOBRE LITERATURA ARGENTINA
}

Analía Gerbaudo

Universidad Nacional del Litoral-CONICET

"La antología" es el título de un poema que Susana Thénon incluye en esa humorada mordaz que es Ova completa. ${ }^{1}$ Un poema que casi veinte años antes de las demoledoras críticas de Slavoj Zizek (1997) a la "agenda multicultural" advierte acerca de la superficialidad de la diferencia pensada como exotismo. Thénon delega la voz a Petrona Smith-Jones, una investigadora norteamericana becada en Argentina para hacer una antología de poesías de mujeres: "pero lo que me importa profundamente/ de tu poesía y alrededores/ es esa profesión -aahh ¿cómo se dice?-/ profusión de íconos e índices”. El efecto que parece buscarse es el rechazo provocado por esta transparencia extrema del supuesto de estas prácticas: "porque tú sabes que en realidad/ lo que a mí me interesa es no sólo que/ escriban/ sino que sean feministas/ y si es posible alcohólicas/ y si es posible anoréxicas/ y si es posible violadas/ y si es posible lesbianas/ y si es posible muy muy desdichadas" (1987:182-183). El sarcasmo se refuerza en el remate del texto: "es una antología democrática/ pero por favor no me traigas/ ni sanas ni independientes" (1987:183). Este personaje que irrumpe en el poema sin control ético por parte de ningún otro expone representaciones estereotipadas no sólo de la sexualidad o de las conductas "sanas" o "patológicas" sino también de los criterios que rigen las agendas de investigación literaria.

Ocuparse de la literatura firmada por mujeres que escriben desde América Latina atendiendo sólo al modo en que ésta exhibe prototipos es también una forma de sortear la pregunta acerca de los aportes literarios que se realizan

\footnotetext{
${ }^{1}$ El poema "Ova completa", incluido en el texto del mismo nombre, realiza ocurrentes juegos a partir de la etimología y apela a un recurso inusual en la poesía: la nota al pie. En ese espacio Thénon anota: "OVA: sustantivo plural neutro latino. Literalmente: huevos. COMPLETA: participio pasivo plural neutro latino en concordancia con huevos. Literalmente: colmados. Variantes posibles: rellenos, repletos, rebosantes, heridos." (Thénon, 1987:155).
} 
desde el continente. ${ }^{2}$ Al mismo tiempo que se exaltan los derechos o los pesares de las minorías evitando la discusión sobre los avatares del capitalismo global (Zizek, 1997), se encubre el desconocimiento del otro como agente capaz de intervenir la producción cultural tanto en el campo de la teoría como en el de la literatura. Valorar las producciones latinoamericanas sólo por su "politización de los contenidos" (Richard, 2007:79) es una acción plagada de equívocos entre los cuales sobresale aquel que habilita que se localice lo político únicamente en este orden, meramente declarativo, disociándolo de los acontecimientos en la lengua que toda escritura (Derrida, 1972, 1984a) gesta.

Este malentendido en Argentina tiene una larga historia por desandar y diferentes manifestaciones entre las que destaca la que se produce cuando se traza una frontera entre escritores "de provincia" y del "centro" unida a la valoración de los primeros simplemente por la (re)presentación de su "zona". Aparente condescendencia que en realidad eclipsa la atención sobre los movimientos singulares que desde el plano estético genera la literatura que se escribe en estas geografías.

Con el objeto de contribuir a desmontar estos esquemas empobrecedores me detengo en las poéticas de tres escritoras que producen desde Santa Fe apartándose de cualquier mandato no dictado por el compromiso con la escritura; actividad que comprende no sólo los procedimientos retóricos y los tópicos que, paradójicamente se centran en el espacio cercano desafiando lo que sus versos pueden, sino también las decisiones respecto de los tiempos de publicación y de los canales de circulación de los textos.

Entre otros núcleos que iré despejando, subrayo que la poesía de Concepción Bertone, Estela Figueroa y Marilyn Contardi está atravesada por las mismas coordenadas: el tiempo pasado y el que transcurre, el espacio cercano y

\footnotetext{
${ }^{2}$ Situación que se replica en el campo de los estudios literarios toda vez que se reduce el rol de América Latina a productora de crítica pero no de teoría. Reducción que se desmiente desde la práctica: la importante producción categorial gestada por la "crítica" y reutilizada por otros investigadores es la refutación más contundente (cf. por ejemplo, entre otros, los conceptos de ciudad letrada, Rama; transcreación, De Campos; superregionalismo, Cándido; regionalismo no regionalista, Sarlo; traducción de teorías, Romano Sued; polémica y discusión, Panesi; globalización y mundialización, Ortiz; sujeto secundario, Dalmaroni; crítica acéfala, Antelo).
} 
el cuerpo como zona de medición de ambos. Quien pone su voz al habla del poema pega su cuerpo sexuado a la letra tejiendo un hilo delgado entre quien se inventa por la palabra y quien firma: "Humana demasiado humana" dice de sí Concepción Bertone mientras parece hablar de otra; como "La forastera" (recienvenida o extranjera aún en sitio "propio") elige representarse Estela Figueroa; como el conjunto de los recuerdos y de momentos que trae su poesía se reinventa Marilyn Contardi desde el margen siempre-otro de la palabra:

\author{
Puedo creer en el crepúsculo ocre \\ que envuelve al níspero \\ en su seda silvestre. \\ (...) \\ En el tordo cantor del aspa \\ del molino que entró \\ a los ojos de la infancia \\ y ahora vuela de nuevo \\ desde la página. \\ En ellos, que están en mí \\ y son lo que yo soy, \\ persisto y creo. (1992:12-13)
}

En Concepción Bertone la identidad se construye más directamente con relación a la herencia de los maestros, no sin revisar las filiaciones iniciales: nada queda hoy del lazo que la unía a Mario Benedetti y muy poco del que la ligaba a Ernesto Cardenal. La apuesta por la escritura "como homenaje a la poesía y a los poetas" (2005:5) se extrema en Citas y en Aria da Capo pero ya había madurado en El vuelo inmóvil: un poemario donde prevalece la afirmación y la palabra que explota las paradojas; los versos que elaboran definiciones a partir de hipérboles, de cuidadosas selecciones de adjetivos, imágenes y envíos ${ }^{3}$ que llevan a César

\footnotetext{
${ }^{3}$ Pueden distinguirse al menos dos formas de envío en la poesía: el directo (que se realiza desde las dedicatorias, los epígrafes, las menciones) y el indirecto (en el que intervienen la alusión, la intertextualidad, la reminiscencia). Ambas se fundan en la herencia (cf. Derrida, 2001a) y en la deuda poéticas. Cuando el poema es firmado por un arrivant (Derrida, 1996a), puede reconocerse en esta operación un intento de inscribir su nombre junto al de un linaje de escritores que forman una tradición con la que se traba un vínculo intentando a la vez hacer lugar a algo "propio": "no hay fidelidad posible para alguien que no pudiese ser infiel", afirma Derrida (2001b:47). Y añade: "Si la
} 
Vallejo, Beatriz Vallejos, Albert Camus, Octavio Paz, Walt Whitman, Eugenio Montale, Jorge Luis Borges, entre otros.

Su obra ${ }^{4}$ inventa una comunidad en la que las distancias temporales y espaciales no son un obstáculo: en la página en blanco convergen los nombres de Juan L. Ortiz y Constantino Kavafis, Charles Baudelaire y Aldo Oliva, Juan Manuel Inchauspe e Irene Gruss, Hugo Padeletti y Juan José Saer, Rubén Sevlever y Nietzsche, Fernando Pessoa y Paco Urondo. De ese conjunto sobresalen "los padres", los posibilitadores de su nacimiento como poeta. Entre el don y la deuda, ${ }^{5}$ sus títulos reiteran una estructura que refuerza la identificación a

herencia consiste simplemente en mantener las cosas muertas, archivos, y en reproducir lo que fue, no es lo que se puede llamar una herencia. No se puede desear ser un heredero o una heredera que no invente una herencia, que no se la lleve a otra parte con fidelidad. Una fidelidad infiel." (47). Este trabajo de "escoger la herencia" ("un heredero no es solamente alguien que recibe, es alguien que escoge, y que se pone a prueba decidiendo" [Derrida, 2001a:16]) que se advierte (entre otras manifestaciones) en el envío, funda y desarrolla una política de la amistad (Derrida, 1994): los arribantes a una comunidad se instalan también a partir de los envíos a la vez que se diferencian de otros miembros y de otros grupos fijando su nombre a través de la marca (Derrida, 1972) que su escritura deja.

${ }^{4}$ Cuando hablo de obra lo hago en los términos de Derrida: aludo no solamente a toda la producción de un escritor (totalidad siempre im-posible que no obstante funciona como motor de las búsquedas del archivista y de algunos investigadores -2001c-) sino también a aquella que se impone como una "aventura", como una nueva experiencia en la lengua (1967).

${ }^{5}$ Don y deuda son conceptos que aparecen unidos en la obra de Derrida (enlazados en el tratamiento de problemas relacionados con la amistad, el tiempo, la muerte, la propiedad, entre otros). El don se equipara a un regalo, a una ofrenda que no genera deuda ya que está al margen de la lógica del intercambio o del trueque. Hay don cuando se olvida lo que se da e incluso, cuando se olvida que se da (una especie de amnesia que incluye el mismo acto de dar). Entre Diderot y Séneca, y con relación al problema del tiempo, Derrida establece una diferencia entre "dar" y "perder". Escribe: "Perder el tiempo sería perder el único bien del que se tiene derecho a ser avaro y celoso, el único, y la propiedad, la única propiedad que cabría 'sentirse honrado de guardar celosamente."' (1996a:18). Hay un matiz axiológico y ético en juego que grita su diferencia cada vez que pensamos que alguien "da" o "pierde" ("da" o "pierde" su vida, "da" o "pierde" su tiempo [Derrida 1991b, 1999]). Esta distinción también atraviesa las prácticas artísticas, intelectuales y de enseñanza: hay una brecha entre quienes imaginan la producción artística o las mediaciones que se realizan desde la crítica y la enseñanza como un don sin deuda y entre quienes las sitúan entre el don y la deuda o sólo desde la deuda. En cada una de esas situaciones se crean lazos que tienen sus derivaciones en las prácticas que los sujetos generan y en las que 
la vez que propicia el recorte de un espacio en el que la propia voz puja por salir para encontrar su lugar: "Pessoa y yo", "Kafka y yo", "Trakl y yo", "Campana y yo", "Algo de Aldo y Glótica mía".

Mientras habla de los otros, mientras (re)presenta a los otros, Bertone inventa también una imagen de sí. La disculpa o a la emergencia tímida de sus versos primerizos ("no soy nada.../ nada más que una mujer/ que escribe" [Bertone, 1973:2]) contrasta con su ubicación en diálogo con "los padres". La figuración de sí y su envío a Pessoa permiten ejemplificar este procedimiento:

\author{
Como hierba crecida entre adoquines \\ de calles alejadas, calles quietas \\ donde la piedra ahoga la gramilla \\ con agua del fregado. De extramuros \\ del alma sofrenada con mil bridas. \\ Dura ayer como hoy. Toda mi vida \\ se exultó como hierba \\ en una grieta. (2004:9)
}

Bertone se expide sobre las revueltas desatendidas en los usos de la palabra. Crítica y poeta a la vez, se posiciona política y éticamente cuando habla, por ejemplo, de las decisiones de Jorge Luis Borges: "Era valiente y no lo supo./ (...) Ya se sabe/ que conceder concilia y ni sus huesos/ hicieron ese trato" (1993:61). La ética y la política de la literatura se definen en la escritura: no ceder ante las presiones respecto de cómo hacerlo, para quiénes, para qué y según qué tiempos son los mandatos que acepta porque vienen de la ley siempre anárquica de esa extraña institución (cf. Derrida, 1980a, 1989).

Tareas del recinto hogareño, recuerdos de infancia, minuciosas descripciones de plantas y de patios, rutinas de la cocina, gastadas ropas de mujeres, calles semidesiertas, atardeceres, amaneceres y entusiastas preparativos para bailes de pueblo. Como Juan L. Ortiz, Marilyn Contardi compone versos que vuelven la mirada sobre su mundo cercano, sólo en apariencia presentado con sencillez: la distancia de su voz con la enunciación coloquial está marcada por la explotación de los juegos con la sintaxis, la elección del léxico, el cruce de lenguas y, muy especialmente, por la disposición en la

se involucran, en las reproducciones y en las resistencias, en los modos de elaborar el duelo por las pérdidas. 
página y la atención a la musicalidad de las palabras reunidas en sus versos en los que reverberan ecos de los poetas con los que se revela en deuda. Estrategias que ostensivamente señalan un labrado de la lengua que grita su carácter de poesía a la vez que, en un mismo movimiento, presenta el lugar de su confín:

\author{
Es tan difícil decir \\ hasta el deseo más simple.
}

Se sucumbe ante tantas cosas. (1992:39)

Como Bertone y Figueroa, Contardi inventa una figuración de sí a partir de su poesía, de lo que dice sobre su gestación, sobre lo que exige, demanda o provoca. Como Juan L., es muy poco lo que necesita para hacer lugar a la escritura. ${ }^{6}$ Elementalidad que presupone un punto de vista respecto de lo que exige el trabajo de poeta, de la administración del tiempo (el único bien que Derrida -1996a- habilita emplear con avaricia):

\author{
Tiempo es todo lo que necesito \\ para escribirte, poema mío. \\ Tiempo... y esa mirada que se hunde \\ en la nube como una mano en la nieve. \\ Tiempo, \\ eso, \\ y algunas otras cosas: \\ el balanceo de la rama bajo mi peso \\ el jugo de las hojas de trébol \\ en la suela de las sandalias. (2000:39)
}

De llamativo poder anticipatorio, un poema de su primer libro caracteriza las notas salientes de la poética que consolida con los trabajos siguientes: no sólo

\footnotetext{
${ }^{6}$ Juan L. Ortiz escribe sobre la exacerbación del consumo rápido de la novedad y la abrumadora im-posibilidad de administrar el tiempo como marcas negativas del mundo contemporáneo. Su dialógica enunciación es parte de su arte poética y descubre su ética y su política literarias: "Sí, estamos todos cansados y nos olvidamos / demasiado del oro del otoño. Acaso la/ revolución consista en lo que el hombre por siglos ha postergado:/ la necesidad del verdadero descanso, el que permite ver/ cómo crecen, día a día, las florcitas."
} 
cifra algunos de sus temas recurrentes sino que señala el lugar que cobra el ritmo y la musicalidad en sus textos dejando espacio para transparentar la falta de urgencia por su publicación (característica compartida con las otras poetas de esta serie):

\author{
Ah, mis poemas \\ los cuido tanto \\ los guardo en una cajita de música \\ que hace sonar todas las letras \\ en su rodillo erizado \\ los verdes atardeceres, los árboles de luz. (1979:50)
}

Sin lugar a dudas Estela Figueroa actúa la discutida tesis de Hélène Cixous de una escritura femenina (Cixous, 1975) ${ }^{7}$ al producir una inscripción que, con independencia del sexo de quien la firme, revela en su entretejido una posición de mujer en tanto pone en acción "la lengua que se hablan las mujeres cuando nadie las escucha para corregirlas" (Cixous, 1986:37). Con desenfado sus versos, en ocasiones cínicos, discuten roles y mandatos desde un intrincado dialogismo. Su imagen como mujer y como escritora se esboza a partir de la reiterada autofiguración en un mundo pequeño, prácticamente circunscrito a su ciudad, el barrio, su casa, los libros, sus hijas, amores, amantes y amigos. E envío a otros poetas, aun a los que admira como Gottfried Benn, ${ }^{8}$ cobra carácter de contienda o de réplica intelectual cuando lo que entra en discusión es el lugar de la mujer en la cultura. La posición, por otro lado, se sostiene desde una enunciación que claramente pretende provocar un acontecimiento de escritura:

\footnotetext{
${ }^{7}$ En 1975 Hélène Cixous publica en L'Arc "La risa de la medusa", el ensayo en el que funda la categoría escritura femenina. En el mismo año escribe una versión modificada del mismo texto, "La joven nacida". De ese escrito destaco su lectura de las oposiciones binarias que sostienen los mitos del falocentrismo. En clara deuda con las políticas de lectura de la desconstrucción y en diálogo con la concepción derrideana de la ley (ver Gerbaudo, 2007), Cixous intenta desconstruir las parejas hombre/masculino y mujer/femenino; más allá de los equívocos generados por la pretensión universalista de la categoría destaco como altamente productiva su intervención a partir de una entonces inaudita posición de género.

${ }^{8}$ Para un análisis más detallado de los envíos de Estela Figueroa a Gottfried Benn y otros autores, ver "Lo que la poesía puede. Nuevas notas sobre una obsesión de la crítica" (Gerbaudo, 2008a).
} 


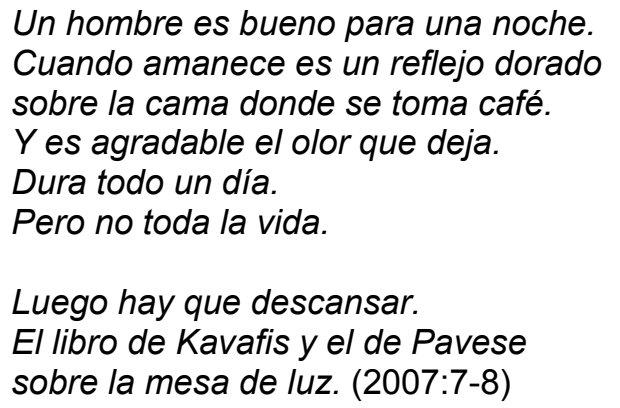

La escritura es para Figueroa una actividad en la que, quien se involucra, no puede conceder(se) nada. "Buscando el poema" es una especie de confesión: cada una de las comparaciones que describen el proceso que concluye con la inscripción está encabezado por un adjetivo que cae sobre sí y que destaca su entrega a la tarea. Asociación que se explota y se potencia a partir de la condensación que genera el último que incluye una sola vez, hacia el final, como un remate:

\author{
Atropellada como un perro. \\ Selectiva como un gato. \\ Lo busco. \\ Fiel como tallada en piedra. \\ Blanda como la espuma. \\ Inocente como un fantasma \\ que vaga por la ciudad. \\ Lo busco. \\ Lejos parece que algo brilla: \\ ¿será el poema? \\ Sobre una cinta de fuego \\ camino a su encuentro. \\ Atropellada. \\ Selectiva. \\ Blanda. \\ Inocente. \\ Despiadada. (2007:46)
}

Por fuera de los estereotipos respecto de la escritura femenina, dejando entrever a veces y en otras ocasiones revelando una densa trama de herencias y apropiaciones, ${ }^{9}$ Concepción Bertone, Marilyn Contardi y Estela Figueroa firman ${ }^{10}$

\footnotetext{
${ }^{9}$ Los resultados de esta parte de la investigación se presentan en el artículo "Escribir (poesía) después de Juan L. Ortiz: una constelación entre el don y la deuda" (Gerbaudo, 2009a).
} 
con su escritura y habilitan que se les aplique la categoría que Beatriz Sarlo inventó para la de Juan L. Ortiz: regionalismo no regionalista es el concepto que permite caracterizar textos desatados de los colorismos tipológicos pero unidos a su zona de enunciación. Textos que responden a poéticas singulares y que forman una constelación que reúne el nombre de Juan L. Ortiz con el de Paco Urondo y el de Juan José Saer en una siempre espectral fundación cargada de mitologías. $^{11}$

Esta fórmula de Sarlo que trae el eco de las paradojas derrideanas me sirve para caracterizar el corpus sobre el que se centra mi investigación en cuyo armado se activa una fantasía de intervención vecina a la de Nelly Richard: en "Un debate latinoamericano sobre práctica intelectual y discurso crítico", apartándose de la crítica que se interesa por objetos "ya sancionados" (2002:901) por las agendas con "función-central” (Derrida, 1967:408), Richard promueve la indagación sobre "políticas y poéticas 'menores' (en sentido deleuziano) cuyas líneas de fuga desvían el control normalizador de la globalización académica" (2002:902).

Mi vuelta sobre textos que si bien han generado movimientos en la literatura ${ }^{12}$ aún no han centrado el interés de la crítica ${ }^{13}$ (en parte, debido a que

${ }^{10}$ Firma con la escritura (Derrida, 1984a, 1991a) quien produce de modo tal que las marcas singulares que genera su apropiación de la lengua permiten identificar sus textos con independencia del copyright, de su nombre y de su rúbrica.

${ }^{11}$ Para un análisis de parte de las "mitologías de la zona" fundadas por una constelación de los escritores del Litoral, ver "Una Kodak para dos: Juan José Saer-Sergio Delgado" (Gerbaudo, 2009b).

${ }^{12}$ Se advierte una relación de deuda poética de Concepción Bertone para con Aldo Oliva y Juan Manuel Inchauspe; por su parte las escrituras de Bertone y de Inchauspe dejan sus marcas en las de Beatriz Vignoli, Francisco Bitar y Osvaldo Aguirre.

${ }^{13}$ De la tesis esbozada remarco la palabra "centrado" a los fines de subrayar que es cierto sector de la crítica el que ha puesto su atención sobre estos autores. Un dato a tener en cuenta: por lo general quienes han escrito sobre Marilyn Contardi, Juan Manuel Inchauspe, Concepción Bertone, Aldo Oliva y Estela Figueroa son también escritores (cf. Aguirre, Battilana, Bellessi, Delgado, Herrera, García Helder, Píccoli, Prieto, Retamoso, Ulla y Bitar en el marco de este mismo Coloquio). Fenómeno que revela una doble atención: la que se origina desde la cercanía en la producción y luego, desde el trabajo de conjetura que exige la intervención crítica entre las que destaco la esbozada por Aldo Oliva en una conferencia dada en 1986 en Santa Fe en el marco del 
quienes los firman rechazan los intentos de direccionamiento temático y estético pero también por sus posiciones sobre los tiempos de publicación, los esquemas de circulación y de difusión), persigue el bosquejo de una cartografía cultural en la que cobran importancia tanto las políticas de archivo ${ }^{14}$ como las de mediación ${ }^{15}$

Primer encuentro Nacional de Literatura y crítica organizado por la Universidad Nacional del Litoral. Con carácter avizor Oliva señala que la poesía que hasta entonces habían escrito Marilyn Contardi, Juan Manuel Inchauspe y Estela Figueroa se inscribe en la literatura argentina; ese lector y escritor exigente que era Aldo Oliva podía entrever en esa constelación un trabajo prometedor con la palabra.

${ }^{14}$ En 1984 Jacques Derrida lee el texto "No apocalypse, not now (a toda velocidad, siete misiles, siete misivas)" en el Coloquio Nuclear Criticism organizado por la revista Diacritics en la Universidad de Cornell. En ese marco presenta un concepto de archivo que luego amplía en otros ensayos (cf. Derrida, 1995, 1996b) componiendo el de política de archivo (enlazado a otros como democracia por venir y literatura). En esta conferencia realiza una distinción entre dos tipos de archivo: los que poseen un referente fuera de sí mismos y los que no. Mientras los primeros pueden reconstruirse en caso de destrucción, los segundos no tienen esa posibilidad y participan por esa precariedad de lo que llama el "caso de la literatura": "la literatura nace y no puede vivir más que su propia precariedad, su amenaza de muerte y su finitud esencial; el movimiento de su inscripción constituye la posibilidad misma de su propio borrarse" (1984b:82). Derrida piensa a partir de la literatura "la totalidad de aquello que, al igual que ella y, desde ese momento, en ella, se halla expuesto a la misma amenaza, constituido por la misma estructura de ficcionalidad histórica, que produce y arrastra consigo su propio preferente" (1984b:82). La historicidad de esta forma del archivo es indisociable de lo que demanda ser interrogado en una "época nuclear": "la literatura pertenece a esta época nuclear, la de la crisis y la de la crítica nuclear, al menos si por ello se entiende el horizonte histórico y ahistórico de una autodestructibilidad absoluta sin apocalipsis, sin revelación de su propia verdad, sin saber absoluto" (1984b:82). Es esta posibilidad de destrucción total la que "gravita sobre la desconstrucción" y la que la orienta ya que ese fantasma le permite estar alerta a "las estructuras y la historicidad propias de los discursos, de las estrategias, de los textos o de las instituciones que es preciso desconstruir" (1984b:81). Como parte de este trabajo, Derrida habla de política de archivo, un concepto caro para quienes vivimos en Argentina ya que exhibe todo lo que nos resta por trabajar para construir una democracia real: para Derrida la política de archivo no es "una cuestión política entre otras" (1995:12) sino que "atraviesa la totalidad del campo y (...) determina lo político como res publica" ya que el poder político se construye y es factible de ser analizado a partir de cómo opera en relación con el cuidado del archivo y, por lo tanto, de la memoria. Si es condición de todo archivo la domicialización (1995:10) es decir, la fijación de una residencia donde este se conserve de modo permanente asegurando el paso institucional entre lo público y lo privado, la "democratización efectiva" se mide, entre otros, por este criterio, es decir, por "la participación y el acceso al archivo, 
que se ejercen desde la crítica y la enseñanza universitaria (zona de intervención sobre la que, como bien señala Miguel Dalmaroni, todavía "sigue pesando la reserva o la sospecha intelectual de algunos circuitos hegemónicos de la crítica" [2008:38]).

En relación con las políticas de archivo, cabe considerar que pretendiendo una distancia con la llorosa e inútil retórica de la falta y asumiendo que formo parte de la misma institución que coloco en el nudo de mis análisis al estudiar sus operaciones, señalo en esta vacancia una productividad: si generar conocimiento exige avanzar sobre aquello que no se sabe, advierto un aporte en la descripción de objetos como los incluidos en este artículo. Por otro lado el estudio de las

a su constitución y a su interpretación" (1995:12). Tesis sobre la que Derrida vuelve con insistencia ligando la literatura con su historia y con la de la democracia: es la democracia por venir como promesa (es decir, como "compromiso con relación a la democracia" [1996b:161] más que como establecimiento de un conjunto estático y determinado de pautas prefijadas) la que deja abierta la posibilidad de actuar otra política del archivo, otra gestión tanto de su conservación como de su preservación contra la amenaza de la pérdida radical, de su conversión a cenizas (cf. Derrida, 1990:405).

En el caso puntual de Argentina, las deudas son muchas. Puntualmente la investigación que desarrollo ha permitido gestionar diferentes restituciones: textos conservados en bibliotecas privadas han sido fotografiados y domicializados en la biblioteca de mi lugar de trabajo (por ejemplo, así se ha procedido con el borrador de una conferencia no grabada de Aldo Oliva y con la revista que ha gestado, El arremangado brazo) o se ha promovido su re-edición o su publicación (esto ha acontecido con los primeros textos de Estela Figueroa y de Concepción Bertone y con una antología de poetas inédita realizada por Concepción Bertone con el subsidio de una Beca de la Secretaría de Cultura de la provincia de Santa Fe [Bertone, 2008]).

${ }^{15}$ Cuando hablo de las prácticas de la crítica y de la enseñanza como mediaciones pongo especial énfasis en el concepto de envío (Derrida, 1980b). Dice Derrida: "cuando se escribe, cuando se enseña, cuando se habla se les está proponiendo a otros un nuevo punto de referencia, un nuevo contrato, una nueva interpretación... El otro es quien tiene que contestar o no." (2001b:40). Destaco de esta posición algunos puntos. Primero: la relación entre qué pueden la enseñanza, la crítica y la teoría y qué depende del receptor. Segundo, la inserción de estas nociones en el marco desde el cual se enuncian: quien apueste a un trabajo de desconstrucción sabe que la intencionalidad de quien emprende la práctica nunca alcanza para asegurar su éxito. Por lo tanto esta conjetura (ligada a las condiciones de desarrollo de la práctica, las características de los destinatarios y las políticas de archivo) permite explicar el carácter constante y a la vez im-posible de una efectiva desconstrucción, de una completa mediación, de un envío sin fisuras, de una enseñanza homóloga a los aprendizajes, de una crítica que se lee tal como quien firma, pretende. 
políticas de archivo y de mediación desarrolladas por la crítica y la enseñanza universitarias en parte explica cómo se ha llegado al actual estado ${ }^{16}$ habilitando líneas de intervención reflexivas sostenidas en los datos existentes.

Desde este lugar subrayo el carácter político y ético de la decisión de escribir poesía desde una provincia apostando a su valor con independencia de las derivas de la crítica y de la siempre inestable bolsa de valores del mercado que en los últimos años compra a alto precio el exotismo que se vende con firma de mujer (si es posible, latinoamericana; y si es posible, del interior del país en cuestión; y si es posible, "muy muy desdichada" ya que en estos casos toda colección, aunque "democrática", necesita su toque folklórico o prototípico siempre que, claro está, se ajuste al patrón de tolerancia existente).

Las firmas de las que me ocupo en este artículo forman, junto a otras, el corpus a partir del cual interrogo y paso revista al canon de literatura argentina que ha armado la universidad desde la reinstalación democrática hasta la fecha a partir de sus mediaciones y de su política de archivo actuando algunas veces en paralelo, otras reforzando, otras rechazando los patrones del mercado. La pregunta sobre lo que resta en la literatura después de (o junto a) los nombres de Manuel Puig, Alejandra Pizarnik, Juan L. Ortiz, Macedonio Fernández, Juan José Saer, Juan Gelman, Rodolfo Fogwill y César Aira (sobre los que la crítica se ha centrado en los últimos años tal como lo muestran las recurrencias de los congresos y de las publicaciones del campo) me ha conducido a los de Juan Manuel Inchauspe, Paco Urondo, Aldo Oliva. Nombres como sinécdoques de obras que en un artículo reciente Sergio Delgado describe como los "momentos privilegiados de encuentro entre una escritura y su época" (2008a:257) dado el modo en que en "situaciones históricas difíciles" quienes las firman conciben "soluciones ejemplares" a "lo político en literatura" (2008a:257). Nombres que junto a los de Marilyn Contardi, Estela Figueroa y Concepción Bertone integran esta historia corta de la literatura argentina poniendo entre signos de pregunta su carácter devaluado.

\footnotetext{
${ }^{16}$ Los resultados de esta parte de la investigación se condensan en el artículo "Importación de teorías en los estudios literarios sobre poesía en Argentina (1957-2007). Derivaciones para la enseñanza de la literatura" (Gerbaudo, 2008b).
} 
No caben dudas de que se ha instalado en la crítica literaria reciente el interrogante respecto de qué firmas se imprimen después de las que la propia crítica contribuyó a colocar en el centro de la vidriera. Si una ensayista con la trayectoria de Adriana Astutti, dueña a la vez de una de las editoriales de mayor poder de instalación en el campo literario, recupera entre la ironía, el humor y cierta dosis de molestia el comentario también irónico de César Aira respecto de que ciertas editoriales de Argentina estarían dispuestas a publicarle hasta un estornudo, ${ }^{17}$ vale interrogar, a propósito de este movimiento, cuáles otros se han estado y se están generando dado el efecto de aparición de nuevos nombres (pienso, simplemente a modo de ejemplo, en el caprichoso canon de Tabarovsky quien selecciona, dentro del que arma la editorial Beatriz Viterbo, un conjunto de títulos que refuerzan las operaciones de los suplementos culturales de mayor difusión en Argentina; actitud no menos pedante que el viejo y no tan olvidado antojo de Bloom quien escudándose en una siempre sesgada lectura hace de lo particular una engañosa sentencia universal), cuáles movimientos llevan al reconocimiento de otros desde un tiempo menos inmediato que el de la intermitencia mediática, el bombardeo periodístico vía los suplementos culturales, la eclosión de los blogs y las urgencias impuestas por la lógica hiperproductivista del mundo académico tal como se concibe y se gestiona en estas latitudes.

Por fuera de ese vértigo y junto a las firmas que desde un regionalismo no regionalista derrotan el paso del tiempo calculando y apostando al valor de lo que resta en literatura desde una ex-temporánea medida y desde anacrónicos aunque admirables posicionamientos sobre la publicación y la circulación, se inscribe la de Sergio Delgado. Sus textos, ajenos a la premura, dejan entrever una apropiación serena de la tradición armada desde "la zona" y logran imprimir su sello en un campo signado por la monotonía de la que participa la atolondrada, efímera e incalculable proliferación precipitada de la "novedad". ${ }^{18}$

\footnotetext{
17 Texto leído por Adriana Astutti durante la presentación del libro El giro autobiográfico de la literatura argentina actual (Giordano, 2008) en Rosario el 20 de marzo de 2009. Para el comentario de César Aira, ver http://adncultura.lanacion.com.ar/nota.asp?nota_id=1105067.

${ }^{18}$ Tal como lo hice en mi lectura durante el Primer Coloquio de la Red La literatura y sus lindes en América Latina, cierro-abriendo a los efectos de mostrar, a partir de los resultados de la investigación en curso, las conjeturas que movilizan las actividades siguientes. En relación con las
} 


\section{Bibliografía}

Aguirre, O. (2000): El general. Melusina, Mar del Plata.

(2006a): Ningún nombre. El pez de plata, Mar del Plata.

(2006b): “Aldo Oliva. Cronología”, en Diario de poesía, N²3:13-14.

(2006c): "La tradición de los marginales", en Tres décadas de poesía argentina (1976-2006), Fondebrider, J. Libros del Rojas, Buenos Aires, 45-56.

(2007): Lengua natal. Ediciones en danza, Rosario.

Aira, C. (2009): "Trato de escribir buenas novelas, pero me salen cosas raras", en La Nación, Suplemento $A D N$, sábado 7 de marzo. Disponible en:

http://adncultura.lanacion.com.ar/nota.asp?nota_id=1105067.

Antelo, R. (2008): Crítica acéfala. Grumo, Buenos Aires.

Astutti, A. (2009): Texto leído durante la presentación del libro El giro autobiográfico de la literatura argentina actual el viernes 20 de marzo en Rosario.

Battilana, C. (2002): “Juan Manuel Inchauspe: la oscura atención”, en Hablar de poesía, $\mathrm{N}^{\circ} 8: 50-55$.

Bellessi, D. (2005): “Una obra firme y compacta”, en La guacha, N²1:5.

Bertone, C. (1973): De la piel hacia adentro. Edición propia, Rosario.

(1983): El vuelo inmóvil. La Cachimba, Buenos Aires.

(1993): Citas. Bajo la luna nueva, Rosario-Buenos Aires.

(2004): Aria da Capo. Ediciones del Dock, Buenos Aires.

(2005): "Aria da Capo es el libro que quería escribir" (Entrevista). La Guacha, N 21:4-10.

(2008): Las 40. Poetas santafesinas 1922-1981. UNL, Santa Fe.

Bitar, F. (2007): Negativos. El niño Stanton, Buenos Aires.

(2009): "Juan Manuel Inchauspe y Poesía Buenos Aires: fundamento y proyección" (ver en este volumen).

Bloom, H. (1994): El canon occidental. Anagrama, Barcelona, 1995.

promesas efectuadas en ese primer coloquio, confieso que mi indagación sobre las operaciones de Beatriz Sarlo en la crítica literaria y en la enseñanza desarrolladas en Argentina después de la reinstalación democrática, aún observa datos incipientes como para hacer lugar a una presentación en estos espacios. 
Cándido, A. (1972): "Literatura y subdesarrollo", en América Latina en su literatura, Fernández Moreno, C. (ed.). S. XXI, México, 334-353.

Cixous, H. (1975): "La joven nacida", en La risa de la medusa. Ensayos sobre la escritura, Moix, A. (ed). Anthropos, Barcelona, 1995:13-107.

(1986): La llegada a la escritura. Amorrortu, Buenos Aires, 2006.

Contardi, M. (1979): Los espacios del tiempo. Fundarte, Caracas.

(1992): El estrecho límite. Ediciones de la Cortada y UNL, Santa Fe.

(2000): Los Patios. UNL, Santa Fe.

Dalmaroni, M. (2006): Una república de las letras. Lugones, Rojas, Payró. Escritores argentinos y Estado. Beatriz Viterbo, Rosario.

(2008): La investigación literaria. Problemas iniciales de una práctica. UNL, Santa $\mathrm{Fe}$.

De Campos, H. (1987): "Reflexión sobre la Transcreación", en Diseminario. La desconstrucción. Otro descubrimiento de América, Block De Behar, L. (ed.). XYZ, Montevideo. 147-156.

Delgado, S. (1994): La selva de Marte. Ediciones de la Cortada, Santa Fe.

(1996): El alejamiento. Beatriz Viterbo, Rosario.

(2001): La laguna. Beatriz Viterbo, Rosario.

(2005): Al fin. Beatriz Viterbo, Rosario.

(2006): Estela en el monte. Beatriz Viterbo, Rosario.

(2008a): "Las posibilidades de la época”, en Cahiers de LI.RI.CO. N4:255-263.

(2008b): Parque del sur. Editorial Municipal de Rosario, Rosario.

(2009): El corazón de la manzana. Mondadori, Buenos Aires.

Derrida, J. (1967): L'écriture et la différence. Du Seuil, Paris.

(1972): La dissémination. Du Seuil, Paris.

(1980a): "La loi du genre", en Parages (Nouvelle édition revue et augmentée).

Galilée, Paris, 2003:233-266.

(1980b): La carte postale, De Socrate à Freud et au-delà. Flammarion, Paris.

(1984a): Signéponge. Columbia University Press, New York.

(1984b): "No apocalypse, not now (a toda velocidad, siete misiles, siete misivas)", en Anthropos. Revista de documentación científica de la cultura. Suplementos, $\mathrm{N}^{\circ}$ 13, 1989:75-86. 
(1989) "This Strange Institution called Literature", en Acts of Literature, Attridge, D. (ed.). Routledge, London, 1992:33-75.

(1990): "Passages -du traumatisme à la promesse", en Points de suspension. Entretiens, Weber, É. (ed.). Galilée, Paris, 1992.385-409.

(1991a): “Contresignatures”, en Points de suspension. Entretiens, Weber, É. (ed.). Galilée, Paris, 1992 :377-383.

(1991b): Donner le temps. 1. La fausse monnaie. Galilée, Paris.

(1994): Politiques de l'amitié. Galilée, Paris.

(1995): Mal d'Archive. Une impression freudienne. Galilée, Paris.

(1996a): Aporías. Morir -esperarse (en) los "límites de la verdad". Paidós, Barcelona.

(1996b): "Notas sobre desconstrucción y pragmatismo", en Desconstrucción y pragmatismo, Mouffe, Ch. (comp.). Paidós, Buenos Aires, 151-170.

(1999): Donner la mort. Galilée, Paris.

(2001a): "Escoger su herencia”, en Y mañana qué..., Derrida, J. y Roudinesco, É. FCE, Buenos Aires, 9-28.

(2001b): “A corazón abierto”, en ¡Palabra! Instantáneas filosóficas. Trotta, Madrid, 13-48.

(2001c): Papel máquina. La cinta de máquina de escribir y otras respuestas. Trotta, Madrid, 2003.

Figueroa, E. (1985): Máscaras sueltas. UNL, Santa Fe.

(1991): A capella. UNL y Ediciones de la nada, Santa Fe.

(2007): La forastera. Recovecos, Córdoba.

García Helder, D. (1992): “Despojo y tensión”, en Diario de poesía, N²2:7-8.

Gerbaudo, A. (2007): Derrida y la construcción de un nuevo canon crítico para las obras literarias. Universitas y Sarmiento editor, Córdoba.

(2008a): "Lo que la poesía puede. Nuevas notas sobre una obsesión de la crítica", en III Congreso Internacional Transformaciones Culturales. Debates de la teoría, la crítica y la lingüística. Facultad de Filosofía y Letras. UBA, Buenos Aires. CDROM.

(2008b): "Importación de teorías en los estudios literarios sobre poesía en Argentina (1957-2007). Derivaciones para la enseñanza de la literatura", en Literatura: teoría, historia, crítica. № 10:95-140. 
(2009a): "Escribir (poesía) después de Juan L. Ortiz: una constelación entre el don y la deuda", en Paradigmas literarios: articulando escrituras y lecturas, Crolla, A. y Vallejos, O. (ed.). UNL, Santa Fe, (en prensa).

(2009b): "Una Kodak para dos: Juan José Saer-Sergio Delgado". Trabajo a presentar en el II Congreso Internacional "Cuestiones críticas" a desarrollarse en Rosario, UNR, octubre.

Giordano, A. (2008): El giro autobiográfico de la literatura argentina actual. Mansalva, Buenos Aires.

Herrera, R. (2000): “Juan Manuel Inchauspe o el poema imposible", en Hablar de poesía, N³:66-73.

Oliva, A. (1986): Cuaderno de apuntes (cedido para ser consultado para esta investigación por sus hijos Ángel y Antonio Oliva).

Ortiz, J. L. (1996): Obra completa (editada por Delgado, S.). UNL, Santa Fe.

Ortiz, R. (1996): Otro territorio. Ensayos sobre el mundo contemporáneo. Universidad Nacional de Quilmes, Buenos Aires, 2005.

(2000): O próximo e o distante. Japao e Modernidade-Mundo. Brasiliense, São Paulo.

(2005): Mundialización: saberes y creencias. Gedisa, Barcelona.

Panesi, J. (2003): "Polémicas ocultas", en Boletín, № 11:7-15.

Píccoli, H. (2006): "La poética de Aldo Oliva", en Diario de poesía. N 73:25.

Prieto, M. (2006): Breve historia de la literatura argentina. Taurus, Madrid.

Rama, Á. (1984): La ciudad letrada. Comisión Uruguaya pro Fundación Ángel Rama, Montevideo.

Retamoso, R. (1995): La dimensión de lo poético. Héctor Dinsmann Editor, Buenos Aires.

(2004): Figuras cercanas. Ensayos sobre poetas de Rosario. Artemisa, Rosario. (2008): Apuntes de literatura argentina. UNL, Santa Fe.

Richard, N. (2002): "Un debate latinoamericano sobre práctica intelectual y discurso crítico", en Revista Iberoamericana, N²00:897-906.

(2007): Fracturas de la memoria. S. XXI, Buenos Aires.

Romano Sued, S. (2003a): Travesías. Estética, poética, traducción. e-books de Fondo Cultural Ediciones, Córdoba. 
(2003b): "Mundos propios, voces ajenas: la otredad y la identidad en la traducción", en El Hilo de la Fábula. N²/3:159-168.

Sarlo, B. (1996): "La duda y el pentimento", en Punto de vista, N 56:31-35.

Tabarovsky, D. (2004): Literatura de izquierda. Beatriz Viterbo, Rosario.

Thénon, S. (1987): Ova completa, en Barrenechea, A. y Negroni, M. (ed.): La morada imposible. Tomo I. Corregidor, Buenos Aires, 2001.135-194.

Ulla, N. (1974): "10 poetas del Litoral", en Crisis, N 17:62-65.

Vignoli, B. (2001): Viernes. Bajo la luna nueva, Rosario-Buenos Aires.

Zizek, S. (1997): "Multiculturalismo o la lógica cultural del capitalismo multinacional", en Estudios Culturales. Reflexiones sobre el multiculturalismo, Grüner, E. Paidós, Buenos Aires, 1998. 